\title{
DIREITOS FUNDAMENTAIS, PETRÓLEO E DESENVOLVIMENTO: OS DESAFIOS DA DESCOBERTA DO PRÉ-SAL BRASILEIRO
}

\author{
FUNDAMENTAL RIGHTS, OIL AND DEVELOPMENT: CHALLENGES OF \\ DISCOVERY'S BRAZILIAN PRE-SALT
}

Matheus Felipe de Castro ${ }^{1}$
Cristhian Magnus de Marco

\section{RESUMO}

O presente artigo sustenta que a Constituição de 1988 projetou um Estado economicamente intervencionista e socialmente assistencial, como instrumento à implementação de um projeto nacional de desenvolvimento, fundado na inovação científica e tecnológica. A descoberta das províncias petrolíferas do Pré-sal em nossa Amazônia Azul impõe novos desafios à realização desse projeto constitucionalmente fundado. O pensamento de Celso Furtado pode fornecer uma fórmula teórica para enfrentar esses novos desafios, (re) formulando as diretrizes políticas da estratégia de desenvolvimento nacional autônomo e soberano, rumo à constituição de um Estado de bem-estar compromissado com a realização do catálogo de direitos fundamentais previsto naquela Carta.

Palavras-chave: Direitos Fundamentais; Pré-Sal; Desenvolvimento.

\section{ABSTRACT}

This article argues that the 1988 Constitution designed a State economically and socially interventionist care, as an instrument to implement a National Development Project, based on scientific and technological innovation. The discovery of oil provinces of the Pre-Salt in our "Blue Amazon" poses new challenges to the realization of this project constitutionally founded. The Celso Furtado's thought can provide a theoretical formula to meet these new challenges, (re) formulating the policy guidelines of the national development strategy autonomous and sovereign towards the creation of a welfare state committed to the realization of the catalog of rights provided that Fundamental Charter.

Keywords: Fundamental Rights; Pre-Salt; Development.

\footnotetext{
${ }^{1}$ Professor e pesquisador do Programa de Mestrado em Direitos Fundamentais da Universidade do Oeste de Santa Catarina-UNOESC, e professor da Escola Superior da Advocacia de Santa Catarina-ESA/SC. Possui Doutorado em Direito pela Universidade Federal de Santa Catarina. E-mail: matheusfelipedecastro@gmail.com ${ }^{2}$ Professor e pesquisador do Programa de Pesquisa, Extensão e Pós-graduação em Direito da Unoesc. Doutor em Direito pela Pontifícia Universidade Católica do Rio Grande do Sul. Editor Adjunto da Revista Espaço Jurídico/Espaço Jurídico Journal of Law. E-mail: cristhian.demarco@unoesc.edu.br
} 


\section{CONSIDERAÇÕES INICIAIS}

O presente artigo partirá do pressuposto que a Constituição de 1988 projetou um Estado economicamente intervencionista e socialmente assistencial, como instrumento à implementação de um Projeto Nacional de Desenvolvimento, fundado na inovação científica e tecnológica, com a finalidade de garantir a efetivação de um amplo rol de Direitos Fundamentais constitucionalmente estabelecidos.

O Desenvolvimento, ele mesmo considerado um Direito Humano Fundamental pela Declaração do Direito ao Desenvolvimento da Assembléia Geral da ONU, de 1986, aparecerá assim como um Direito Fundamental Instrumental, entendida essa instrumentalidade como um meio para se atingir outros fins, ou seja, - Desenvolvimento concebido como um meio eficaz para a garantia de outros Direitos Fundamentais finais para os homens individualmente considerados ou para a coletividade.

Outrossim, as recentes descobertas das províncias petrolíferas do Pré-sal em nossa "Amazônia Azul" impôs novos desafios à realização desse projeto constitucionalmente fundado, na medida em que gera uma perspectiva de abundância de divisas que precisam ser bem direcionadas pela gestão estratégica nacional à realização de valores e projetos constitucionalmente admitidos.

O pensamento de Celso Furtado pode fornecer uma fórmula teórica para enfrentar esses novos desafios, (re) formulando as diretrizes políticas da estratégia de desenvolvimento nacional autônomo e soberano, rumo à constituição de um Estado de bem-estar compromissado com a realização do catálogo de direitos fundamentais previsto naquela Carta, eis que esse autor dedicou toda a sua vida acadêmica ao estudo do Desenvolvimento político, social e econômico, além de haver estudado, quando membro da CEPAL, o caso emblemático da Venezuela, país da América do Sul que, naquele momento histórico, embora possuidor de 
grandes jazidas de Petróleo, não fora capaz de direcionar a abundância de divisas geradas com o óleo para a superação dos seus graves problemas sociais.

Portanto, para além da empolgação inicial com as descobertas, há que se questionar se a simples abundância de divisas derivadas do extrativismo desse bem primário garantiria, por si só, a realização do tipo de projeto de desenvolvimento nacional esquadrinhado na Constituição de 1988, com geração e distribuição de trabalho e renda para toda a sociedade brasileira, ou se poderia, até mesmo, gerar o efeito contrário, gerando um complexo processo de desindustrialização e conseqüente estagnação do Parque Produtivo brasileiro.

A pergunta-problema da pesquisa é importante na medida em que nações exportadoras de petróleo como a Venezuela e a Arábia Saudita, embora detentoras de grandes bolsões petrolíferos permaneceram subdesenvolvidas e com grandes desigualdades sociais internas, embora tenham conseguido gerar abundância de divisas com o extrativismo do óleo. Nesses casos, somente algumas elites foram beneficiadas, sem que as grandes massas populacionais tivessem sido realmente beneficiadas com o aumento do produto interno bruto, o que parece ter sido determinante para a estagnação do sistema de Direitos Fundamentais desses povos.

O referencial teórico do trabalho será fundado, além da bibliografia básica dos Direitos Fundamentais, na obra de Celso Furtado, principalmente no seu recémreeditado livro "Ensaios sobre a Venezuela: subdesenvolvimento com abundância de divisas", obra de referência para a tentativa de desvendar o nó que se coloca entre as políticas gerenciais de Estado e a efetivação de um Programa de Direitos Fundamentais constitucionalmente garantido. Pretende-se a todo momento realizar um diálogo interdisciplinar entre Direito, Teoria Política e Teoria Econômica, com a finalidade de se alcançar um resultado teórico com capacidade de colaborar pragmaticamente para o aperfeiçoamento das instituições nacionais.

Como se percebe, a discussão rondará a velha polêmica em torno da diferença entre Desenvolvimento ("lato sensu") e crescimento, e a pré-compreensão de que o primeiro não se confunde com acúmulo inorgânico de divisas, sendo um 
Direito Fundamental complexo, gerador de profundas transformações políticas, econômicas e sociais capazes de garantir melhorias significativas na qualidade de vida de uma nação, enquanto o segundo, parece se aproximar mais de um mero conceito econômico que não expressa os incrementos reais nos índices de desenvolvimento humano de um povo historicamente determinado.

Este será o objeto do presente artigo: identificar o modelo de projeto de desenvolvimento político, econômico e social definido pela Constituição de 1988 , questionando como a abundância de divisas derivadas da extração petrolífera do Pré-sal pode colaborar para a realização do "horizonte constitucional de aspirações" do povo brasileiro, garantindo a efetividade do Direito Fundamental do Desenvolvimento e dos Direitos Fundamentais gerais que dele podem derivar.

\section{O PROJETO DE DESENVOLVIMENTO NA CONSTITUIÇÃO DE 1988 E OS DIREITOS FUNDAMENTAIS}

O grande desafio que se impõe agora para os democratas e nacionalistas brasileiros é a realização da Constituição da República Federativa do Brasil, de 1988, uma Carta de feições avançadas, que projetou a construção de uma sociedade melhor, politicamente soberana, economicamente desenvolvida e socialmente justa e igualitária, marcada por um amplo projeto de efetivação de Direitos Fundamentais civis, sociais e ambientais, capaz de projetar para um futuro próximo uma sociedade de Bem-Estar social (Grau, 2006, p. 47), com ampla erradicação das graves vulnerabilidades externas e crônicas disparidades internas que fazem sofrer o povo brasileiro (Guimarães, 2005, pp. 259-267).

Constituições nascem para morrer (dada a dimensão temporal do seu ser), ou seja, para que suas metas sejam realizadas, colocando, nessas condições, a necessidade da construção de novos projetos civilizacionais mais avançados ainda. A derrota de um projeto constitucional representa, nesse passo, evidente retrocesso, enquanto a vitória de uma Constituição representa verdadeiro salto dialético de um 
povo na história, o que projeta a sua dimensão programática não como um sonho de realização postergada, mas como uma meta a ser alcançada imediatamente.

A Constituição de 1988 sofreu as vicissitudes históricas e políticas de seu tempo. Nascida keynesiana/schumpeteriana numa quadra histórica de avanço das políticas neoliberais pelo mundo, acabou sofrendo fortes ataques por parte de setores políticos não compromissados com a soberania e o desenvolvimento nacionais. No entanto, principalmente após a crise financeira que abateu a economia estadunidense a partir de 2007, a sua ideologia adotada (Souza, 2002, pp. 04-05) iniciou um processo de revitalização e fortalecimento que coloca a perspectiva, após duas décadas de sua promulgação, de criação das condições para a sua realização histórica.

Ora, por tudo isso, uma Constituição não é uma coisa que se possa manipular, tocar, sentir, como um objeto físico. Ela é uma realidade embora não comungue da mesma realidade que o mundo natural. Pelo contrário, ela é a expressão de relações sociais concentradas e juridicizadas num dado momento histórico e que nos dão a dimensão da relação entre pessoas concretas. Não a velha relação sujeito-objeto, do positivismo, mas a relação sujeito-sujeito, do póspositivismo (Streck, 2009, p. 92). Portanto, a Constituição não é uma coisa, mas uma relação social, política e jurídica.

Ademais, se é uma relação concentrada e juridicizada, expressa o projeto político de um povo em seu devir (Furtado, 1975, p. 131). Estudar a Constituição de um povo é um exercício de compreensão do seu ser na dimensão tridimensional do tempo, onde o passado funda as condições objetivas das quais se parte para, no presente colocar o campo das práticas sociais e políticas, com um futuro que propõe o quadro de possibilidades ou as encruzilhadas históricas para onde se caminha. Uma Constituição, portanto, não é um produto, mas um processo de transformação.

A Constituição da República Federativa do Brasil, de 1988, dessa forma, é o retrato mais fiel da evolução política do povo brasileiro, não no sentido de que faça um retrato do que o Brasil é nos dias atuais - evidentemente, a sociedade que ali está descrita não é a sociedade que se tem, mas a que se deseja ter - mas no 
sentido de que, partindo de uma realidade com todos os seus problemas concretos, desenha as metas e propõe os meios para a superação dessa realidade, rumo a algo de melhor do que se tem no presente. Portanto, a Constituição não é um retrato, mas uma meta a ser alcançada.

Portanto, primeiramente, há que se identificar na Constituição de 1988, o modelo de desenvolvimento nacional que ali foi concebido, mediante ampla e democrática discussão pelos constituintes de 1988, com vistas a construção dessa sociedade melhor, justa e solidária, identificando, outrossim, os meios que a Carta dispôs para realização desse projeto ${ }^{3}$.

Ora, numa nação nascida do Colonialismo, pensada e fundada como empresa extrativista para exportação de bens primários (Prado Júnior, 1992, p. 118), o mercado interno (articulação da produção de bens manufaturados com o trabalho e o consumo) não foi valorizado, dificultando a dinamização da economia nacional de forma mais ou menos independente. O mercado externo sempre rondou, como uma sombra, a economia nacional, que acabou ficando dependente dos humores dos mercados internacionais, das crises financeiras e institucionais das nações altamente industrializadas.

Pensando nessa realidade, a Constituição de 1988 elegeu o mercado interno como eixo central da política de desenvolvimento nacional, quando afirmou, em seu artigo 219, que o mercado interno integraria o patrimônio nacional e seria incentivado de modo a viabilizar o desenvolvimento cultural e sócio-econômico, o bem-estar da população e a autonomia tecnológica do País (Grau, 2006, p. 254).

Uma nação detentora de um forte mercado interno, constituído por empresas nacionais consolidadas e competitivas diante das empresas multinacionais nos mercados globalizados, aliado à valorização da renda do trabalho e do mercado consumidor, sempre foi uma fórmula de sucesso para o desenvolvimento, tendo sido, inclusive, a forma adotada pelos Estados Unidos da América em seu processo de industrialização que o levou a se consolidar como nação mais dinâmica do

\footnotetext{
3 O tema foi analisado em CASTRO, 2009. Para uma visão ampla e crítica da matéria, ver também: BERCOVICI, 2005.
} 
capitalismo mundial, no século XX. Aliás, "eles [os países altamente desenvolvidos] não seriam o que são hoje se tivessem adotado as políticas e as instituições que agora recomendam às nações em desenvolvimento" (Chang, 2004, p. 13).

Por outro lado, numa nação tradicionalmente agrícola e produtora de produtos primários, os constituintes de 1988 perceberam que o desenvolvimento do mercado interno deveria se operar a partir da valorização dos setores de alto valor agregado, principalmente o setor de inovação tecnológica. Assim, o artigo 218, da Constituição de 1988, determinou que o Estado promoveria e incentivaria o desenvolvimento científico, a pesquisa e a capacitação tecnológicas, sendo que a pesquisa tecnológica voltar-se-ia preponderantemente para a solução dos problemas brasileiros e para o desenvolvimento do sistema produtivo nacional e regional.

O projeto desenhado na Constituição de 1988 é um projeto que bate de frente com uma tradição centenária de nossa economia nacional: ela sempre foi primária (produtora de matérias primas), de baixíssimo valor agregado (abrindo mão de transformar as matérias primas que produz para revender bens manufaturados), exportadora (fundada nos mercados externos), portanto uma economia privada de dinamismo.

Esse cenário de nossa realidade acaba por condicionar um mercado de trabalho enfraquecido, dependente das flutuações dos mercados externos e um mercado consumidor sem poder de compra, fazendo girar a roda viva da dependência e do subdesenvolvimento, da qual não se sai sem uma determinação clara e enérgica em sentido contrário, como a prevista constitucionalmente, ou seja: fundada na dinamização do mercado interno, na valorização do setor produtivo, principalmente através da inovação tecnológica, elemento indispensável para a construção de uma economia capitalista dinâmica.

Como facilmente se observa, trata-se de um típico projeto de fundo schumpeteriano, onde a inovação tecnológica é concebida como "motor do desenvolvimento" (Schumpeter, 1997, pp. 69-100), permitindo a uma nação como a brasileira sair do velho esquema subordinado onde, diante da depreciação dos 
termos de intercâmbio, é obrigada a produzir cada vez mais bens primários para comprar, nos mercados internos, cada vez menos bens manufaturados.

Esse projeto, assim concebido, assume foros revolucionários na medida em que se percebe que a quebra do velho esquema econômico implica, também, a quebra do velho esquema político da divisão internacional do trabalho, que localiza o Brasil na parte mais débil da relação Centro/Periferia, do capitalismo mundial, razão pela qual se vê com clareza por que o modelo de desenvolvimento previsto na Constituição de 1988 não interessa para o "condomínio hegemônico de poder" (Guimarães, 2005, p. 289 e Furtado, 1975, pp. 21-34.), constituído pelas nações já altamente desenvolvidas e que pretendem manter suas vantagens comparativas diante de nações que, agora, estão se desenvolvendo aceleradamente, principalmente mediante indução planejada do Estado.

Ocorre que a Constituição de 1988 não se limitou a traçar um avançado projeto de desenvolvimento nacional fundado na valorização do mercado interno dinamizado pela inovação tecnológica. Foi além e formatou a feição do agente que teria, ao seu sentir, a função precípua de realizar aquele projeto. Como se sabe, em sua Teoria do Desenvolvimento Econômico, Schumpeter concebia o "Empresário Inovador" como o agente principal do desenvolvimento, o sujeito encarregado de impulsionar as forças produtivas, mediante novas combinações, conferindo a um sistema econômico suas características dinâmicas (Schumpeter, 1997, pp. 129-153).

Os constituintes de 1988 entenderam que, diante da importância da tarefa traçada, tal papel dinamizador e dirigente do desenvolvimento não poderia ficar nas mãos da iniciativa privada (ou de empresários inovadores individualmente considerados), que se guia pela lógica da maximização dos lucros/minimização dos custos, que é uma lógica estritamente econômica.

Ao contrário, a Constituição, ao fixar um modelo de desenvolvimento para o Brasil, não o fez com fundamento em razões instrumentais ou numa racionalidade de fundo econômico, com vistas a aumentar o produto interno brasileiro inorganicamente, mas com fundamento em razões políticas e sociais de melhoria e elevação dos padrões de qualidade da vida de seu povo, o que pressupõe que o 
aumento da produção e da riqueza nacionais possa ser redistribuído na forma de trabalho, educação, saúde, assistência, cultura, lazer, moradia, saneamento, segurança, transporte, participação política, enfim, na construção de uma verdadeira democracia política e econômica.

Diante dessa lógica, caberia ao Estado o papel de Empresário Inovador, um Political Developer (Castro, 2009, p. 23), encarregado de identificar gargalos e situações, empreendendo, mediante planejamento consciente, políticas de desenvolvimento com vistas a construir o projeto constitucionalmente traçado e garantindo que o produto econômico do desenvolvimento possa ser revertido em produtos políticos e sociais que garantam a construção da sociedade livre, justa e solidária sonhada pelos brasileiros e brasileiras que conceberam a Carta Política de 1988. Nesse sentido, um aparelho de Estado de modelo liberal seria absolutamente insuficiente para a realização da meta traçada (Bercovici, 2005, p. 58).

Ressalte-se que a escolha constitucional pelo Estado como sujeito dinamizador do desenvolvimento, para nós, brasileiros, não teve um caráter arbitrário nem foi guiada por meras opções ideológicas. Respeitou, isso sim, a realidade brasileira, que sempre encontrou no Estado esse papel de impulsionador das relações de produção. O Brasil foi uma nação pré-capitalista, fundada, primeiro, no modo de produção escravista e, depois, num modo de produção coronelista (fundado na peonagem) e só conseguiu superar essa situação, se industrializando mediante a intervenção de um Estado de novo tipo, nascido da Revolução de 1930, que se propôs prioritariamente a construção de uma economia de mercado no Brasil, o que efetivamente ocorreu até o Milagre Econômico (Guimarães, 2005, p. 168, e Buonicore, 2009, p. 187).

A percepção de que no Brasil não foi a economia, deixada por si mesma, o fator condicionante do político mas, ao contrário, que foi a esfera do político que revolucionou a economia nacional, amoldando-a mediante um planejamento consciente; bem como a percepção de que no mundo globalizado economias sem dinamismo tem grandes dificuldades de se desenvolver sem a colaboração da esfera política - não conseguindo concorrer com empresas de nações altamente 
desenvolvidas que, ademais, encontram no Estado anteparos protecionistas que trabalham para manter sua hegemonia - foi o determinante para que os constituintes de 1988 outorgassem ao Estado nacional brasileiro esse papel de agente ativo do desenvolvimento.

O Estado traçado na Constituição de 1988, encarregado de realizar o projeto de desenvolvimento nacional, é um Estado de modelo intervencionista/social, no sentido de que se constitui como aparelho político-empresarial de intervenção no terreno econômico (planejamento/ indução/ participação em setores econômicos estratégicos, mediante suas empresas públicas e de economia mista), com o fim de amoldar a economia nacional a fins politicamente traçados; e como aparelho previdenciário, no sentido de que se responsabiliza por implementar formas de redistribuição da riqueza nacional entre seu povo, mediante políticas fundadas numa legítima Justiça Redistributiva, buscando atingir um regime de relativas igualdades materiais, com superação das profundas disparidades sociais e regionais internas.

É indisfarçável a ascendência keynesiana de um Estado assim concebido, eis que foi esse pensador (J. M. Keynes) quem idealizou o Estado como o salvaguardador político do modo capitalista de produção, diante das crises que o abalam ciclicamente, eis que a doutrina do "laissez faire", fundada na lógica do lucro máximo, leva inevitavelmente as economias nacionais e internacional a crises de superprodução, inclusive financeiras, que abalam a convivência social, ocasionando fome, desemprego, guerras e outros "efeitos colaterais" próprios do capitalismo.

Foi por isso que optamos por designar esse tipo de Estado de "Capitalista Coletivo Ideal", ou seja, uma forma política que assume para si a administração da dinâmica econômica de uma nação com vistas não à realização de interesses meramente privados, mas de interesses públicos (coletivos), partindo de uma lógica ideal fundada em um projeto político-social determinado. O "Capitalista Coletivo Ideal" é a forma do Estado brasileiro traçado pela Constituição de 1988: um political developer das forças produtivas nacionais com fins de construção de uma nação politicamente soberana e democrática, economicamente desenvolvida, tecnologicamente autônoma e socialmente justa e solidária(Castro, 2009, p. 23). 
Nessa medida, o Desenvolvimento foi previsto pela Declaração do Direito ao Desenvolvimento da Assembléia Geral da ONU como um Direito Humano Fundamental instrumental. Isso quer significar que o Desenvolvimento não é um fim em si mesmo, mas um complexo de transformações sociais, econômicas e políticas capazes de elevar sobremaneira a qualidade de vida de um povo, garantindo-Ihe bem-estar e segurança existencial, como se pode perceber da leitura dos seguintes excertos da Declaração:

\section{Artigo 1}

1. O direito ao desenvolvimento é um direito humano inalienável em virtude do qual toda pessoa humana e todos os povos estão habilitados a participar do desenvolvimento econômico, social, cultural e político, a ele contribuir e dele desfrutar, no qual todos os direitos humanos e liberdades fundamentais possam ser plenamente realizados.

\section{Artigo 2}

1. A pessoa humana é o sujeito central do desenvolvimento e deveria ser participante ativo e beneficiário do direito ao desenvolvimento.

\section{Artigo 6}

1. Todos os Estados devem cooperar com vistas a promover, encorajar e fortalecer o respeito universal pela observância de todos os direitos humanos e liberdades fundamentais para todos, sem distinção de raça, sexo, língua ou religião.

2. Todos os direitos humanos e liberdades fundamentais são indivisíveis e interdependentes; atenção igual e consideração urgente devem ser dadas à implementação, promoção e proteção dos direitos civis, políticos, econômicos, sociais e culturais.

3. Os Estados devem tomar providências para eliminar os obstáculos ao desenvolvimento resultantes da falha na observância dos direitos civis e políticos, assim como dos direitos econômicos, sociais e culturais.

\section{Artigo 8}


1. Os Estados devem tomar, a nível nacional, todas as medidas necessárias para a realização do direito ao desenvolvimento e devem assegurar, inter alia, igualdade de oportunidade para todos em seu acesso aos recursos básicos, educação, serviços de saúde, alimentação, habitação, emprego e distribuição eqüitativa da renda. Medidas efetivas devem ser tomadas para assegurar que as mulheres tenham um papel ativo no processo de desenvolvimento. Reformas econômicas e sociais apropriadas devem ser efetuadas com vistas à erradicação de todas as injustiças sociais. (ONU, 1986).

A Declaração não deixa dúvidas sobre a importância do Desenvolvimento como meio instrumental para a realização dos demais Direitos Fundamentais previstos por uma nação em sua Carta Constitucional. A Constituição de 1988 também reconheceu o Desenvolvimento como um objetivo nacional. O artigo $3^{\circ}$ daquela Carta, chamado por Bercovici (2005, pp. 36-37) de "Cláusula Transformadora", afirma que:

Art. $3^{\circ}$ Constituem objetivos fundamentais da República Federativa do Brasil:

I - construir uma sociedade livre, justa e solidária;

II - garantir o desenvolvimento nacional;

III - erradicar a pobreza e a marginalização e reduzir as desigualdades sociais e regionais;

IV - promover o bem de todos, sem preconceitos de origem, raça, sexo, cor, idade e quaisquer outras formas de discriminação (BRASIL, 1988).

Os quatro incisos da "cláusula transformadora" da realidade brasileira não podem ser lidos isoladamente, compondo antes um conjunto de ações da competência do Estado, em sua busca de construção das condições materiais para a efetivação dos Direitos Fundamentais de todo o povo nacional. Não é possível imaginar que o Estado possa garantir a expansão e a efetividade dos Direitos Fundamentais civis (liberdades "lato sensu"), bem como dos Direitos Fundamentais sociais e ambientais, sem paralelamente garantir que o Desenvolvimento se torne 0 elemento viabilizador dessa realização.

\section{SUBDESENVOLVIMENTO COM ABUNDÂNCIA DE DIVISAS: A DESCOBERTA DO PRÉ-SAL BRASILEIRO}


Identificado o modelo do projeto brasileiro de desenvolvimento e o agente constitucionalmente responsável pela sua implementação, cumpre-nos abordar a questão fantástica do descobrimento do pré-sal brasileiro, e as potencialidades desenvolvimentistas que o seu advento coloca para o futuro nacional.

Ora, exatamente no momento em que se busca dar a guinada desenvolvimentista que a Constituição previu, de uma produção primárioexportadora para outra, secundária, dinamizada pelo mercado consumidor interno e fundada na inovação tecnológica, surge uma nova fonte de matérias-primas naturais, que restaura o potencial brasileiro para a produção primária, com um gigantesco potencial de vantagens comparativas diante de um mundo que começa a sentir os primeiros sinais da escassez de fontes não renováveis de energia.

Trata-se de fechar os olhos, mais uma vez, para o projeto constitucional, que traz em-si um gigantesco potencial libertário para a nação e o povo brasileiro, se apegando mais uma vez à extração de um bem primário como o petróleo para exportação, ou de direcionar as divisas obtidas com essa extração para a realização do projeto constitucionalmente traçado?

O fato é que o potencial extrativista do pré-sal não pode ser negligenciado e deve ser utilizado pelo Estado brasileiro com toda a parcimônia que a situação exige, levando em consideração: 1) a situação ainda subdesenvolvida do Brasil e 2) a perspectiva de abundância de divisas no território nacional em médio e longo prazo. Vejamos o que significam essas duas situações.

Há muito se abandonou o conceito de subdesenvolvimento como uma "etapa" que nações periféricas do capitalismo mundial teriam que percorrer para chegar ao desenvolvimento (Furtado, 1971, p. 187 e 2000, p. 80). Essa noção linear da história, acabou por transferir "modelos" de desenvolvimento das nações ditas desenvolvidas para as subdesenvolvidas, o que efetivamente não colaborou para a construção de sociedades melhores.

Os pensadores ligados a CEPAL, principalmente a figura exponencial de Celso Furtado, deram uma imensa contribuição para a compreensão do problema do 
subdesenvolvimento, quando perceberam e passaram a tratar esse estado existencial não como uma etapa, mas como uma relação de poder entre nações localizadas no eixo Centro/Periferia da economia mundial (Furtado, 1971, p. 236).

Para esse pensamento, as nações capitalistas se dividiriam em nações centrais, de economia dinâmica e inovadora, e nações periféricas, de capitalismo não dinâmico e sem capacidade inovadora. As primeiras produtoras de bens secundários, de alto valor agregado e as segundas produtoras de bens primários para as primeiras.

Essa relação de poder Centro/Periferia, ao contrário do que se imaginava no pensamento etapista anterior, não obra no sentido de que as nações periféricas venham a integrar o seleto grupo das nações desenvolvidas, mas, ao contrário, trabalha no sentido da manutenção deste establishment. As vantagens comparativas das nações desenvolvidas frente às subdesenvolvidas se descortinaria através da compreensão de uma histórica depreciação dos termos de intercâmbio entre as nações, onde os produtos produzidos no centro tem seus preços elevados progressivamente e os produzidos na periferia tem seus preços diminuídos também de forma progressiva.

Ou seja, cada vez mais as nações periféricas teriam que produzir mais bens primários (sem valor agregado) para importar cada vez menos bens de alto valor agregado, aumentando $o$ fosso da desigualdade entre as nações $e$, conseqüentemente, a transferência de mais-valia produzida nas nações periféricas para as centrais, permitindo que essas construíssem sociedades de bem-estar calcadas sob a condição da miserabilização crescente das populações trabalhadoras localizadas nas nações periféricas: a condição de prosperidade de uns tornava-se a condição da miserabilização de muitos outros.

Portanto, interessaria às nações centrais e desenvolvidas a manutenção da relação de subdesenvolvimento, eis que o desenvolvimento periférico afetaria de forma profunda o seu bem-estar interno, gerando não somente instabilidades econômicas, como também políticas, que sempre colocam em cheque as cristalizadas estruturas de poder dominante. 
As nações periféricas, ao aceitar esse esquema, estariam abrindo mão do seu futuro, da perspectiva de transformação de suas estruturas sociais. Evidentemente, as pressões internas nessas nações para manutenção desse esquema foram sempre gigantescas, eis que também nelas, o desenvolvimento coloca em cheque velhas e cristalizadas posições de poder que alteram significativamente a correlação das forças políticas e sociais internas, principalmente das elites nacionais ligadas ao setor exportador, que se constituíram como sóciasgerentes dos interesses das grandes potências no interior de suas nações.

Daí que qualquer projeto de desenvolvimento que se proponha a quebrar o esquema de poder hegemônico tanto no nível interno quanto externo sofra evidentes resistências por parte de amplos setores econômicos que dele se beneficiam (Buonicore, 2009, p. 123) e não possam ser implementados sem uma grande mobilização social em torno dele. Daí que o projeto revolucionário da Constituição de 1988 tenha sofrido grande resistência por parte das forças políticas defensoras do neoliberalismo, que inclusive tentaram subverter o texto constitucional, num evidente procedimento de "fraude constitucional", como ressaltou Bonavides (2000, pp. 178-179).

Nos últimos anos o Estado brasileiro conseguiu reverter razoavelmente as tentativas de liberalização de sua estrutura, tendo conseguido, inclusive, implementar programas de aceleração do desenvolvimento que revitalizaram o papel do Estado na indução planejada do crescimento econômico, recuperando seu papel constitucional de agente do desenvolvimento. As privatizações de empresas públicas foram estancadas e novas foram criadas, demonstrando que a forma de Estado concebida em 1988 ainda tem gigantescos potenciais de construção da sociedade melhor ali concebida.

Igualmente, uma política externa bem direcionada para a defesa dos interesses nacionais conseguiu reverter profundas vulnerabilidades externas que tornavam o país historicamente dependente não somente de nações desenvolvidas como de organismos financeiros internacionais. Dívidas históricas foram liquidadas e 
o Brasil pôde assumir um papel mais efetivo no concerto internacional das nações, numa quadra histórica de multipolarização do poder mundial.

O mercado interno se revitalizou como importante dinamizador do consumo; empresas nacionais entraram para o restrito rol das grandes empresas multinacionais; a produção secundária do país superou a primária em matéria de geração de valor; o mercado de trabalho se aqueceu, gerando mais de treze milhões de empregos formais numa população total de cento e noventa milhões de habitantes.

Mas muito ainda há por fazer para que o país se liberte das amarras históricas do subdesenvolvimento e se consolide como nação capitalista tecnologicamente inovadora e independente. Ainda nos encontramos na posição de importadores de tecnologia de ponta. Nações inovadoras como EUA e Japão ainda nos impõe seus padrões de consumo, mantendo o monopólio de setores tecnológicos estratégicos. O investimento em química fina, em nanotecnologia, em tecnologias da informação e inteligência artificial ainda são muito pequenos em relação a outras nações. Nosso potencial energético nuclear é brecado pelas nações que já consolidaram esse potencial.

Eis que a perspectiva da abundância de divisas proporcionada pela extração do óleo do pré-sal coloca para o povo brasileiro o problema da articulação deste excedente para a resolução desses problemas e consolidação definitiva do projeto de sociedade melhor definido na Constituição. Finalmente o Brasil tem a oportunidade histórica para tanto. A pergunta talvez seja "como"?

\section{A “FÓRMULA CELSO FURTADO” E O DESENVOLVIMENTO BRASILEIRO}

Na década de 1950, Celso Furtado foi convidado, como membro da CEPAL, a desenvolver um relatório sobre o desenvolvimento venezuelano, apontando perspectivas de longo prazo para o crescimento econômico com distribuição de renda para o povo daquela nação e que deram origem a dois escritos que 
recentemente foram publicados no Brasil reunidos sob o título "Ensaios sobre a Venezuela: subdesenvolvimento com abundância de divisas” (Furtado, 2008).

As análises de Furtado sobre o caso venezuelano são paradigmáticas do funcionamento de economias subdesenvolvidas que, em virtude da descoberta de jazidas de riquezas naturais, passam a contar, rapidamente, com excedentes de divisas internas (Furtado, 2008, p. 42).

A constatação de Furtado é que apesar de a economia venezuelana ter sido acometida por excesso de divisas, principalmente em ativos cotados na moeda norte-americana, o país vinha permanecendo subdesenvolvido e o volume de riquezas expresso na conceituação abstrata do $\mathrm{PIB}$, não correspondia efetivamente a uma melhoria significativa de todos os extratos sociais distribuídos nacionalmente (Furtado, 2008, p. 56).

A renda per capita do povo venezuelano era apontada, à época, como uma das maiores da América Latina, mas bem se sabe que o conceito trata de uma relação matemática, onde se divide de forma bastante simples a renda nacional (produto interno bruto, descontados os gastos de depreciação do capital e os impostos indiretos) pelo número de habitantes da nação, ocultando, no entanto, as disparidades internas de distribuição de renda e a própria concentração que acaba por separar os muito ricos dos muito pobres ou miseráveis.

Dessa forma, Celso Furtado percebera que o excesso de divisas, no caso da Venezuela, vinha trazendo mais prejuízos que benefícios para o povo venezuelano, e isso por uma total ausência de clareza na implementação de políticas efetivas de desenvolvimento por seus dirigentes políticos. O seu raciocínio foi o seguinte:

Nações subdesenvolvidas, como a estudada, são nações localizadas na periferia do capitalismo mundial, entendido o subdesenvolvimento não como uma fase para se alcançar o desenvolvimento, mas uma relação de poder onde os desenvolvidos só são desenvolvidos porque mantém os subdesenvolvidos no subdesenvolvimento.

Nações subdesenvolvidas, como a estudada, sofrem grande pressão dos mercados internacionais para manter uma "especialização" de suas economias na 
produção de bens primários, com baixíssimo valor agregado, deixando de investir no setor secundário, de transformação, e abrindo mão de um desenvolvimento tecnológico próprio.

Nações subdesenvolvidas, como a estudada, possuem um parque industrial ainda não consolidado ou em vias de consolidação, não apresentando poderio econômico e mesmo influência política necessária para concorrer, interna ou externamente, com mega-corporações internacionais, principalmente norteamericanas e européias.

Dessa forma, a invasão da economia nacional por um excesso incontrolado de divisas, acaba provocando a valorização cambial da moeda local frente à moeda referencial de troca em nível internacional (o dólar). Com o dólar barato e a moeda nacional valorizada, torna-se mais barato e cômodo importar bens manufaturados das nações já plenamente industrializadas, do que produzi-los e adquiri-los internamente, pressionando a indústria nacional ao achatamento dos seus preços e conseqüentemente, pressionando pela bancarrota em massa da produção industrial interna, fechando o ciclo que pressiona para uma nação se manter fundada numa economia estacionária, de tipo primário (Furtado, 2008, p. 123).

Aqui se encontrava, para Furtado, o busílis, a pedra de toque da questão e que explicava o continuado subdesenvolvimento venezuelano, apesar de um excesso de divisas provocado pela extração e venda do petróleo in natura. A simples derrama de divisas internamente não era suficiente para direcionar o desenvolvimento a um tipo que atendesse as necessidades da distribuição da renda e da melhoria da qualidade de um povo de forma mais ou menos homogênea. $A$ economia, deixada por si mesma, levava à perplexidade do "crescimento do bolo" sem qualquer perspectiva concreta de sua divisão.

Para Celso Furtado, a solução evidente estaria na intervenção consciente do Estado (da esfera do eminentemente político) diante dessa invasão de divisas, direcionando-as para a industrialização nacional (Furtado, 2008, p. 125), principalmente no terreno da inovação tecnológica (Furtado, 2008, p. 62), o que pressionaria para que o país deixasse sua condição subdesenvolvida, estacionária e 
produtora-primária para alcançar uma condição desenvolvida, com uma economia secundária e dinâmica.

Por outro lado, paralelamente ao esforço do direcionamento da economia nacional para um outro modelo, seriam necessárias outras duas frentes, uma política e outra social: a) a reformulação dos processos de participação política do povo no poder, aprofundando a democracia (soberania popular), o que evidentemente tem o condão de movimentar as elites locais, alterando substancialmente relações cristalizadas de poder; b) um esforço social no sentido de gerar emprego e renda em massa, em frentes de trabalho altamente qualificadas, não se esquecendo da mãode-obra não qualificada, que precisaria ser alocada em setores que pudessem absorver rapidamente esse excedente industrial de reserva (Furtado, 2008, pp. 125135).

Ou seja, o desenvolvimento não seria o produto econômico de uma visão abstencionista de mundo, mas o produto político de um esforço político direcionado a realização de reformas estruturais que alteram: a) a forma de relacionamento político do povo com o Estado, construindo e desenvolvendo a própria democracia; b) a forma da distribuição social da renda entre todos os nacionais, com elevação dos padrões de vida das amplas camadas populares, com fundamento no trabalho e no emprego formal; c) a forma da economia nacional, antes fundada numa estrutura estacionária e primária e, agora, fundada numa estrutura dinâmica e secundária, com ênfase principalmente na inovação tecnológica.

É exatamente essa concepção não eurocêntrica de conceber o rompimento das nações subdesenvolvidas com as amarras que as pressionam para permanecer enredadas nas teias dessa relação de poder, que é o subdesenvolvimento, que chamamos neste trabalho de "Fórmula Celso Furtado" e que em tudo se aplica ao Brasil.

O fato é que o Brasil, como se viu no primeiro capítulo deste trabalho, já possui uma definição clara e precisa de uma política de desenvolvimento nacional, que foi traçada originariamente na Constituição de 1988 e que determina ao Estado brasileiro a realização de esforços no sentido de superar as graves disparidades 
internas e as crônicas vulnerabilidades externas nacionais e que em tudo se encontra com o pensamento de Celso Furtado sobre o desenvolvimento brasileiro e latino-americano.

A pergunta fundamental é: como direcionar as divisas do pré-sal brasileiro para que elas possam realizar o projeto político de desenvolvimento nacional inscrito na Constituição de 1988? Como direcionar essas divisas para a realização do ideal de construir no país uma sociedade livre, justa e solidária, capaz de erradicar a pobreza e a marginalização, reduzindo as desigualdades sociais e regionais? Como direcionar essas divisas para que elas não pressionem uma desindustrialização do nosso parque industrial nacional? Como direcionar essas divisas para o aprofundamento da democracia no Brasil? Como direcioná-las para a criação de um regime de pleno-emprego, com participação mais efetiva dos salários no produto interno bruto? Como elevar o bem-estar do povo brasileiro? Evidentemente, as perguntas já trazem em si as respostas e soluções para os problemas levantados.

\section{CONSIDERAÇÕES FINAIS}

O pensamento de Celso Furtado sobre o desenvolvimento das nações subdesenvolvidas compõe uma verdadeira sinfonia de acordes com os dispositivos desenvolvimentistas da Constituição de 1988. A ideologia constitucionalmente adotada, nesse passo, bebeu muito do pensamento da CEPAL e do seu ilustre representante.

No entanto, a Constituição de 1988 sofreu as agruras de nascer desenvolvimentista no momento exato onde o neoliberalismo avançava sobre o mundo, ditando uma "nova" ordem mundial fundada numa repaginação do velho "laissez faire", ressuscitado das cinzas da Crise financeira de 1929.

Passados mais de 20 anos de seu advento, a Constituição vem sendo retomada pelas forças políticas progressistas e democráticas de nossa nação, 
dentre elas pelos juristas engajados na realização do seu projeto revolucionário e transformador.

Sua ideologia apregoa uma fórmula segura para a construção de uma sociedade melhor: o desenvolvimento nacional fundado na inovação tecnológica e no produto do trabalho, com ampla participação dos trabalhadores na renda nacional.

No entanto, apesar do seu parque industrial medianamente avançado, o Brasil ainda sofre as pressões das relações internacionais de poder para manter-se numa posição subdesenvolvida, sem dar o grande salto para uma produção fundada na inovação, mantendo as ainda existentes e profundas desigualdades sociais tão conhecidas.

A descoberta de um novo "Eldorado" coloca a perspectiva de uma rápida invasão de divisas na economia interna, pressionando a valorização cambial de nossa moeda frente ao dólar, o que teria efeitos deletérios para os produtores nacionais, que não conseguiriam manter a concorrência diante de produtos manufaturados em outras partes do mundo, principalmente na Ásia e, especialmente, da República Popular da China.

O Estado brasileiro precisa intervir conscientemente nesse processo, obrando para direcionar essas divisas para o desenvolvimento de três frentes paralelas (política $=$ aprofundamento democrático; econômica $=$ aperfeiçoamento do parque tecnológico nacional e social = geração de emprego e renda), com o fim de garantir a realização do projeto de uma sociedade melhor que a Constituição de 1988 resumiu como um "horizonte de aspirações possíveis" de nosso povo no devenir de sua história.

\section{REFERÊNCIAS BIBLIOGRÁFICAS}

BERCOVICI, Gilberto. Constituição econômica e desenvolvimento: uma leitura a partir da Constituição de 1988. São Paulo: Malheiros, 2005. 
BONAVIDES, Paulo. Curso de Direito Constitucional. 9. ed. São Paulo: Malheiros, 2000.

BUONICORE, Augusto. Marxismo, história e revolução brasileira: encontros e desencontros. São Paulo: Anita Garibaldi e Fundação Maurício Grabois, 2009.

CASTRO, Matheus Felipe de. Capitalista coletivo ideal: o Estado e o projeto de desenvolvimento nacional na Constituição de 1988. 643f. Tese (Doutorado em Direito) - Centro de Ciências Jurídicas da Universidade Federal de Santa Catarina, Florianópolis, 2009.

CHANG, Ha-Joon. Chutando a escada: a estratégia do desenvolvimento em perspectiva histórica. São Paulo: Unesp, 2004.

FURTADO, Celso. A hegemonia dos Estados Unidos e o subdesenvolvimento da América Latina. 2. ed. Rio de Janeiro: Civilização Brasileira, 1975.

Ensaios sobre a Venezuela: subdesenvolvimento com abundância de divisas. São Paulo: Contraponto, 2008.

Introdução ao desenvolvimento: enfoque histórico-estrutural. 3. ed. São

Paulo: Paz e Terra, 2000.

Teoria e política do desenvolvimento econômico. 4. ed. São Paulo:

Companhia Editora Nacional, 1971.

GRAU, Eros Roberto. A ordem econômica na constituição de 1988: interpretação e crítica. 11. ed. São Paulo: Malheiros, 2006.

GUIMARÃES, Samuel Pinheiro. Desafios brasileiros na era dos gigantes. Rio de Janeiro: Contraponto, 2005.

PRADO JUNIOR, Caio. História econômica do Brasil. São Paulo: Brasiliense, 1992.

SCHUMPETER, Joseph Alois. Teoria do desenvolvimento econômico. São Paulo: Nova Cultural, 1997.

SOUZA, Washington Peluso Albino de. Constituição econômica. In: - Teoria da constituição econômica. Belo Horizonte: Del Rey, 2002.

STRECK, Lenio Luiz. Hermenêutica jurídica $e(m)$ crise: uma exploração hermenêutica da construção do direito. 8. ed. Porto Alegre: Livraria do Advogado, 2009.

ONU. Declaração do Direito ao Desenvolvimento da Assembléia Geral da Organização das Nações Unidas, de 1986. Disponível em: < 
http://www.direitoshumanos.usp.br/index.php/Direito-ao-

Desenvolvimento/declaracao-sobre-o-direito-ao-desenvolvimento.html >. Acesso em: 20 de março de 2013.

BRASIL. Constituição Federal de 1988. Constituição da República Federativa do Brasil.

São Paulo: Saraiva, 2013. 